This item was submitted to Loughborough's Research Repository by the author.

Items in Figshare are protected by copyright, with all rights reserved, unless otherwise indicated.

\title{
The cultivation of adaptability in Japan
}

PLEASE CITE THE PUBLISHED VERSION

http://www.openhouse-int.com/

\section{PUBLISHER}

(c) Open House International Association

\section{VERSION}

VoR (Version of Record)

\section{LICENCE}

CC BY-NC-ND 4.0

\section{REPOSITORY RECORD}

Eguchi, Toru, Robert Schmidt, Andrew R.J. Dainty, Simon A. Austin, and Alistair G.F. Gibb. 2019. "The Cultivation of Adaptability in Japan". figshare. https://hdl.handle.net/2134/8468. 
This item was submitted to Loughborough's Institutional Repository (https://dspace.lboro.ac.uk/) by the author and is made available under the following Creative Commons Licence conditions.

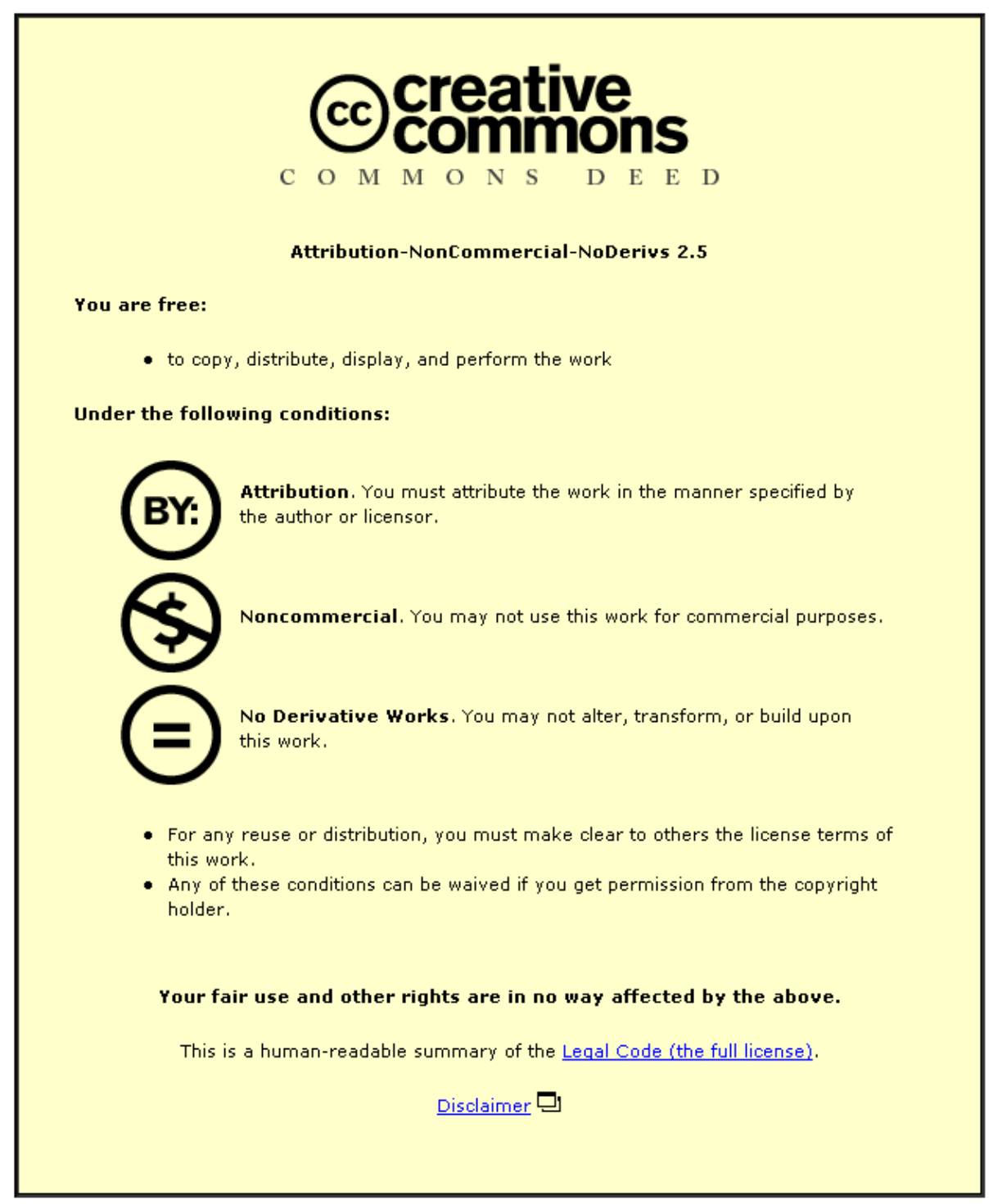

For the full text of this licence, please go to: http://creativecommons.org/licenses/by-nc-nd/2.5/ 


\title{
THE CULTIVATION OF ADAPTABILTY IN JAPAN
}

\author{
Toru Eguchi, Robert Schmidt III, \\ Andrew Dainty, Simon Austin \& Alistair Gibb
}

\begin{abstract}
This paper explores the adaptability of buildings in Japan from the perspective of three distinct practice typologies: large general contractors, large architectural design firms, and small design ateliers. The paper illustrates the cultivation of adaptability in Japan revealing a maturing of concepts into current innovations, trends, priorities, and obstacles in relation to adaptability in design. The paper contextualizes the situation by reviewing the evolution of residential development in support of building adaptability, and the ways in which these policies and concepts have shaped practice and transcended residential design. This evolution is then explored through non-residential case studies undertaken by the three practice types, and supported through a review of critical themes emerging from the interviews. The importance of particular physical characteristics are examined including storey height, location of services, planning modules and structural spacing/spans. The interviews expose the critical relationship between adaptability and different social variables - the state of the market, the role of planning regulations and other legal frameworks; as well as, the misconceptions and variations in the perceptions on the role and meaning adaptability has in practice. The paper is concluded by revealing the lessons learnt, including the unfolding of dependencies outside the 'black box' of adaptability (e.g. practice culture, material and, stakeholder mindsets) and the requirement of effective communication of concepts to allow an informed conversation between professionals and with clients and users. Like many other philosophical design concepts in complex processes, adaptability benefits from a mutual understanding, good relationships, communication, integration, and shared goals amongst team members.
\end{abstract}

Keywords: Adaptability, Japan, Design Practice, Design Parameters, Office Design.

\section{INTRODUCTION}

The majority of buildings are designed and constructed to suit a particular purpose at a certain time, with relatively little thought for their future use or adaptation. The Adaptable Futures research group (AF) is investigating the development of adaptable buildings in the UK that can better accommodate uncertain futures (Gibb et al 2007, Schmidt III et al 2009a). The investigation seeks to operationalize adaptability as a definable design characteristic, stressing the significance of "time" and "layers" as key design constructs (e.g. Duffy 1990, Brand 1994, Schneider and Till 2007). Our current definition of adaptability reflects our accrued journey, namely the capacity of a building to accommodate effectively the evolving demands of its context, thus maximizing value through life' (Schmidt III et al 2010). "Time" as a design consideration suggests buildings as dynamic systems that interact with a set of evolving endogenous and exogenous demands requiring a capacity to accommodate change spatially and functionally through life (e.g. Till 2009, Venturi and Scott Brown 2004, Douglas 2006). Achieving greater adaptability arguably demands a shift away from the current emphasis on form and function in response to immediate priorities towards this time-based view of design. Layers concern the organization of, and interfaces between, components of varying life spans and functions (e.g. Rush 1985, Leupen et al. 2005, Slaughter 2001). They provide a convenient way of decomposing the building based on rates of change, and establish a system for understanding a building's technical capacity to accommodate change (Schmidt III et al 2009b).

The aim of the paper is to illustrate the cultivation of adaptability in Japan by revealing a maturing of design concepts into technical innovations, trends, priorities, and obstacles to realizing 


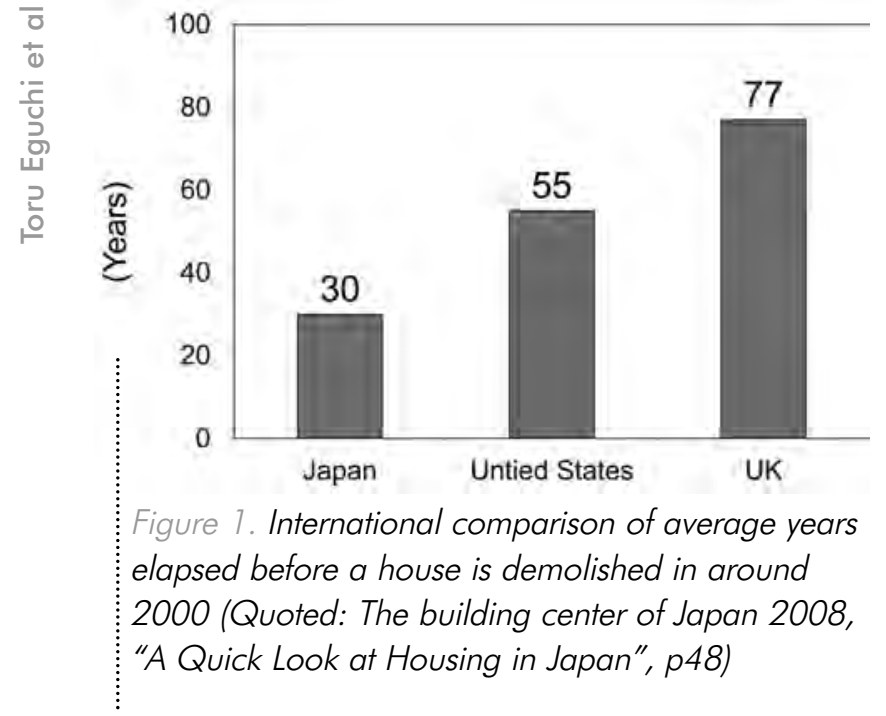

adaptable designs. The findings are then reflected upon and augmented through further work in preparation for a second stage of interviews.

\section{Japanese context}

Historically the life expectancy of Japanese buildings is much shorter than that of western countries (see Figure 1) and the ratio of maintenance and renovation to the total investment lower (e.g. In 2005 , only $24 \%$ of Japanese building work was maintenance and rennovation compared to approximately $50 \%$ in France, Netherlands and UK, Figure 2).

This implies that Japanese buildings are rebuilt within a short period and new construction dominates the market. On the other hand, adaptability as a design feature has long been associated with Japanese housing. Whilst the approach to office design has begun to shift in recent years due to changing market conditions and priorities aligning more with the emerging sustainability agenda, the Japanese construction industry has begun to realize the advantages adaptability can provide in reducing environmental impact, increasing costeffectiveness, and satisfying client desires. The emergence of design considerations for adaptability under two disparate building typologies (housing and office design) render Japan an interesting context within which to explore the development of such buildings.

This part of the AF research explores the attitudes and mindsets of designers to understand how current processes/ projects either impede or enable

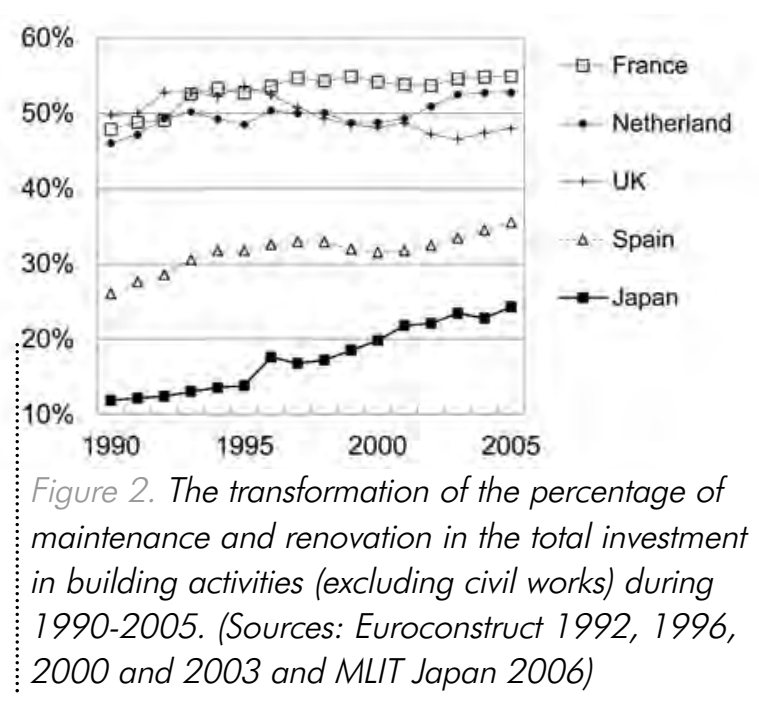

adaptability to manifest. There are clear linkages here extending adaptability beyond the physical artefact to the distributed control concept - a central principle of Open Building (Kendall et al 1999).

\section{JAPANESE 'LONG LASTING' HOUSING}

The move away from traditional house construction was originally driven by an effort to produce a large amount of houses due to the severe shortage in the middle of the 20th Century following WWII. In a 1968 census, the number of total residential units was greater than the total number of households. At this time, Japanese housing policies moved from quantity to quality (Building Center of Japan 2008) with a focus on adaptability.

\section{Traditional Japanese Houses}

Originating from Chinese temple construction, the entire house is based on a single philosophy of measurement - the distance between column centres known as a ken - making it easy to change and extend. Both the widths and depths of all spaces are multiples of this standard unit and form the frame of reference for the remaining components - timber structure, tatami mats ( 2 mats $=3.3 \mathrm{~m} 2=1$ tsubo), doors, and furniture (Hirai, 1998). The house contains no load bearing walls and uses a system of thin columns (width 12-15cm: fits within outer wall), beams, and trusses (wagoya) that can be removed or extended in a straight forward manner. Rooms 
are seperated and connected to the exterior with light double sliding windows and partitions (fusuma) allowing them to be shifted or stored easily. Traditional Japanese rooms bore no functional labels, rather as multi-functional spaces or wa-shitsu meaning a largely empty stage deriving its identity from its temporary occupants (Nute 2004).

\section{KEP: Kodan-Experimental housing Project (1973-)} In the 1970s, the housing industry shifted to respond to the demand of various types of housing and their quality. KEP was an experimental project conducted by the Japanese Housing Corporation in order to incorporate flexibility and adaptability into housing from 1973. They categorized the building into structural frame and four subcategories of components - exterior, interior, kitchen \& bath and other devices (piping, wiring etc.). The intention was to identify interface details between each category and facilitate the use of "open" components.

\section{Century housing system (1980-)}

This system divides the building parts into five categories to prolong life expectancy, based on experience and estimated life expectancy: 1) the main structural members, which are the most difficult to replace lasting 50 to 100 years; 2) roofs, exterior doors and windows lasting 25-50 years; 3) partitions and furniture lasting 12-25 years; 4) home appliances, piping and wiring lasting 6-12 years; and 5) light bulbs and sealants, lasting 3-6 years. The central philosophy is that buildings need to be designed so that parts with long life spans are not damaged when parts with short life spans are replaced (Utida 2002). This system facilitates the future maintenance and exchange of parts as a response to changes in residents or residents' life styles.

\section{SI: Skeleton Infill (1990s-)}

This system supplies buildings in two steps; first " $\mathrm{S}$ " (skeleton) which signifies the long-lasting part and social property and second "I" (Infill/ fit-out) which represents the short-lasting part and private property (NEXT2 1 editorial committee 2005). However, in general, most of the Japanese construction industry tends to recognize this system as a physical issue, such as "S" means structural frame and "I" means interior and services. This is despite its origins deriving from the open building approach of John Habraken, which incorporates more of the softer issues such as decision making levels in the management of residential areas. The NEXT 21 project by Osaka Gas in 1993 is the most famous project in Japan and both public and private sectors were brought together to develop SI technologies in experimental and practical projects (Kendall et al 1999). The Japanese government still uses SI in their policies helping this concept gain widespread dissemination in Japan.

\section{0-year Housing (2006-)}

In 2006, the Basic Plan for Housing (National Plan) indicated a transition to a stock-based housing policy leading to the promotion of the "200-year Housing" initiative which aims to extend the useful life of housing (Minami 2009). This concept involves the construction of houses that boast excellent durability and are easy to manage and maintain (MLIT Japan et al. 2008). This most recent policy incorporates SI thinking, but is diffused through nine chapters focused on minimizing operational consumption and the promotion of 'good' building principles and 'routine' actions to prolong the life of the building.

Each policy and practice iteration has produced more explicit and refined considerations towards time and layers as a way of communicating adaptability. Through the years, an experiencebased progression has added clarity, simplifications, priorities and knowledge about how buildings change through life, developing a matured understanding.

\section{LEARNING FROM JAPAN}

While the number of projects constructed around these policy initiatives represents a small percentage of total construction in Japan, the concepts have pervaded the industry (Utida 2002). All of the interview participants had excellent prior knowledge about the initiatives and often used them as a basis of which to discuss how they addressed adaptability outside of the housing market. It was clear that policies had affected designers' attitudes, whilst a wider dissemination did not occur due to a lack of 
demand in the market and society as a whole. As mindsets in Japan (and across the world) have begun to amalgamate along the sustainability agenda, a more accepting market and tenable culture has arisen bolstering a renewed interest in implementing these concepts in industry. While the interviews provide a mixture of positive and negative perspectives, the non-domestic case studies suggest clear evolutions of the housing culture in Japan.

It should also be noted that many reports on Japan's construction industry have drawn lessons from the management process(es) and technologies associated with the industrialized housing sector (e.g. Gann 1996, Barlow et al. 2003, Barlow et al. 2005, Bottom et al. 1996) which makes up approximately $25 \%$ of the housing market in Japan (a small percentage of the total construction market). While aspects of these technologies and processes have been applied outside this small portion of the industry, what makes the learning from Japan intriguing stems not from these technical fetishes but from fundamental differences in culture and mindsets yielding different possibilities. Buntrock (2002) makes lucid all of the small fundamental differences in culture which promote a much more collaborative and integrated process which often is facilitated through much of the same technologies used in western cultures.

Thus, this is not meant to be a series of lessons extrapolated from Japan and recontextualized for UK implementation, but a narrative presenting a slow transition of attitudes towards a more adaptable future. It illustrates the gap between idealistic principles (mindset) and the volatile contingences of practice (built construct) and demonstrates how concepts, while potentially premature for implementation, can pervade thinking and slowly permeate through tactical shifts towards a better way of operating, as the evolution of policies are not iterations of radical thinking, but grounded in a constant refinement/ modernization of traditional Japanese housing. Within this context, the paper offers a look at how different practice typologies have adapted these concepts through three non-domestic case studies and how physical and social variables play a contingent role.

\section{METHODOLOGY}

Qualitative data was collected for this exploratory exercise through semi-structured interviews with thirteen high-level personnel from six architectural practices. Japanese practices fall into three distinct categories: large general contractors, large architectural design firms and small design ateliers. Large general contractors offer a complete package, ranging from property acquisition, design, construction, maintenance, R\&D and so on. According to company profiles as of 2009, the top five companies have more than 2000 licensed architectural designers in house. Large architectural design firms deal mainly with the design stage of relatively large projects (e.g. more than 10,000 m2 total floor area office buildings). They will also get involved with Construction Management (CM) and Project Management (PM) businesses as well. The larger companies have about 300-700 licensed architectural designers. Small design ateliers typically consist of a few dozen people and deal with relatively small projects, such as private housing. World-famous architects' offices are included in this category. Two design practices were interviewed from each of the three categories.

A series of questions regarding adaptability were developed and emailed to interviewees prior to the interviews directed at exploring a high-level understanding from a practice and professional perspective (e.g. as a company, do you tend to think about future changes?; as an architect, how do you design for adaptability?), and a more specific understanding espoused at a project level (e.g. what enabled or impeded adaptability to manifest in this project?). The aim was to understand the practice as an arena for change and the architectural profession as a facilitator for such change. They were then asked to use specific projects as vehicles to articulate how their practice and professional perspectives are operationalized through specific factors that influenced the adaptability of the design. In the email, the questions were preceded by our definition of adaptability (time and layers) and illustrated through six high-level strategies for adaptability (e.g. available, flexible, refitable) that together formed part of our AF Framework (Figure 3). In addition, a building layer diagram (Brand 1994) was adopted to visually 


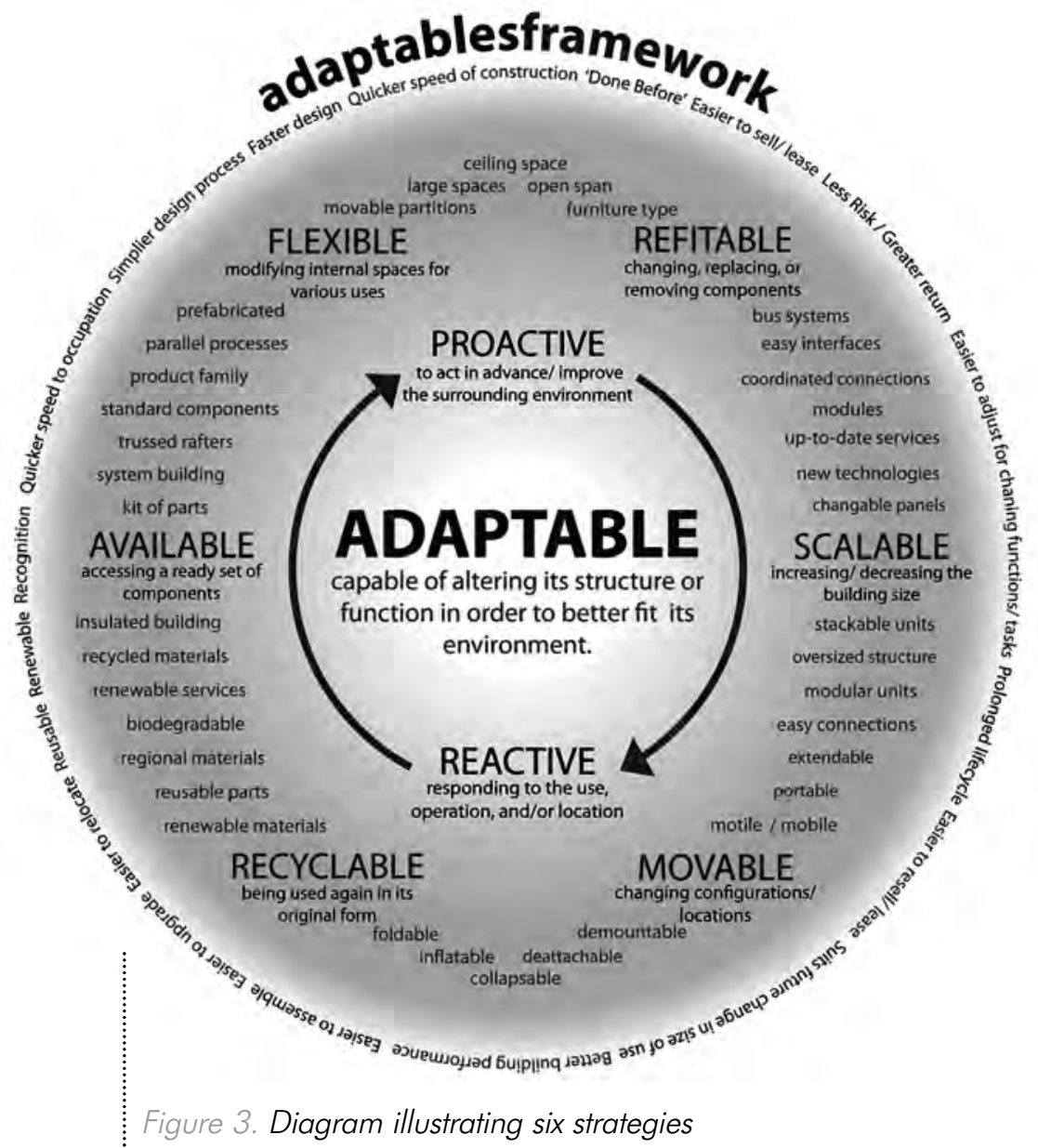

convey how the strategies could be related to different areas of the building.

Data from the interviews were tabulated (generating three A3 size pages) mapping the responses of each practice typology to each question. A thematic content analysis was conducted through a systematic comparison of each cell revealing several themes (e.g. spatial, functional, componentry). We present a description of three projects as case studies (one from each practice typology) followed by a discussion of the key themes that emerged across the six interviews.

\section{CASE STUDIES}

\section{Takenaka Corporation Tokyo Main Office (large general contractor)}

Takenaka Corporation constructed its Tokyo headquarters in 2004 (33,000m2 and 7 stories) with three major themes: 1) high efficiency (a high quality work place for employees); 2) green building; and 3 ) low cost solution (initial and total life cycle cost) (Figure 4). The implementation and convergence of these three aspirations turned the conventional office layout inside out by positioning more static core spaces along the periphery and opening the center up for communication and interaction, allowing the design to accommodate ongoing changes in office operations and environment (Figures 5-6). A key tactic was shifting to a $10.8 \mathrm{~m}$ uniform-grid offering a low cost solution, which is typically used for shopping centres and parking - in contrast to the typical office span of $16-18 \mathrm{~m}$. The reduced column spacing is accompanied by external lateral bracing that creates a rigid shell and allows for a free internal space that was envisioned to incorporate future changes in use (e.g. a hotel or shopping centre). The openness of the space is complimented by a storey height of $4.1 \mathrm{~m}$ with an open and protruding ceiling ranging from a minimum of $3.1 \mathrm{~m}$ in height to a maximum of $3.8 \mathrm{~m}$ providing a good acoustical environment.

The convertibility of the solution is augmented by the decentralization of mechanical and electrical services into 10 modules along the east and 


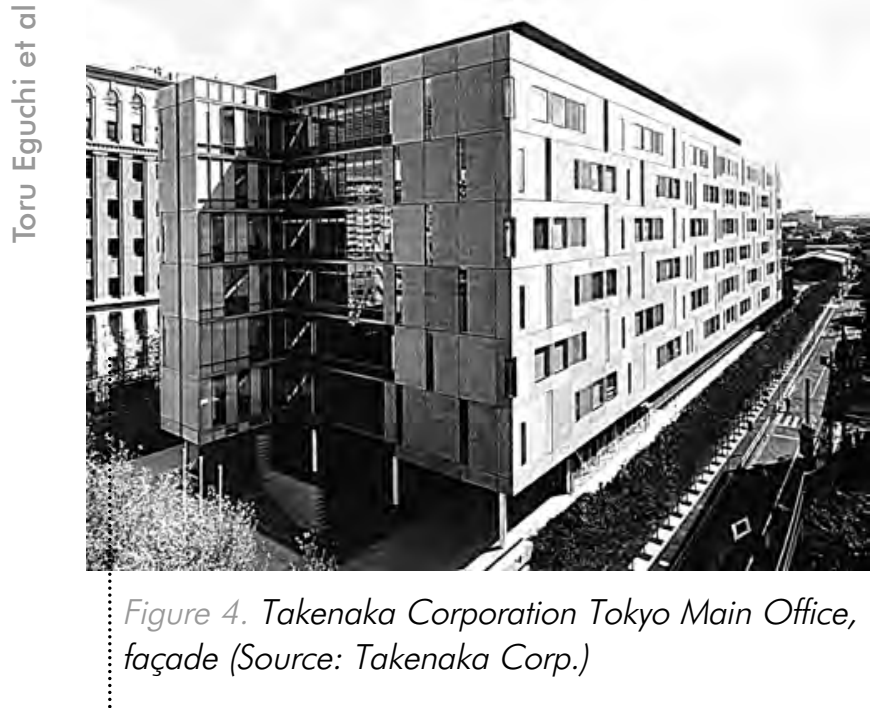

west periphery. The air conditioning units are positioned under the lateral bracing, linked vertically at the rooftop and accessed from both outside and inside. The modules also provide power and communications and help supplement change of use through their distributed control. Natural air is taken from the louvers on the other side, and is distributed through the building on the underside of 'universal floor beams' (standard depth steel beams and girders of $450 \mathrm{~mm}$ ) through aluminium coated cardboard ducts. The strategic use of cardboard ducts is a simple innovation providing improved construction efficiency and lower cost.

The dispersing of the centralized core creat- ed an open solution allowing for continuity (visual connection and access) between floors, spaces and nature through large light wells. The dynamic central zone provides a diverse range of open meeting spaces adopting eye-catching colours and shapes (e.g. diverse angles, shell-shaped partitions) not found in other areas. The furniture is movable and adjustable to stimulate diverse forms of communication. Previously, a wide-range of desk types were used to articulate an employee's position and division, but in this case desks were standardized into two workstations reflecting the types of tasks to be carried out (Takenaka 2005).

\section{Mokuzai Kaikan (large architectural design practice)}

Mokuzai Kaikan (Wood Wholesalers Union, MK) was designed as an innovative prototype for urban wooden offices, based upon earlier traditional structures of Japanese housing and buildings such as temples and shrines, which aimed to revive this culture in Japanese architecture (Figure 7). Traditionally, the structure is made only by timber without steel, concrete, or wet connections (e.g. glue) and is based on a single module - to ease changing layouts and componentry. In MK they use some structural steel parts, but they are removable, being fastened through dry connections. In gener$\mathrm{al}$, there are strict regulations regarding fire resistance in Japan, so to use timber as a component in

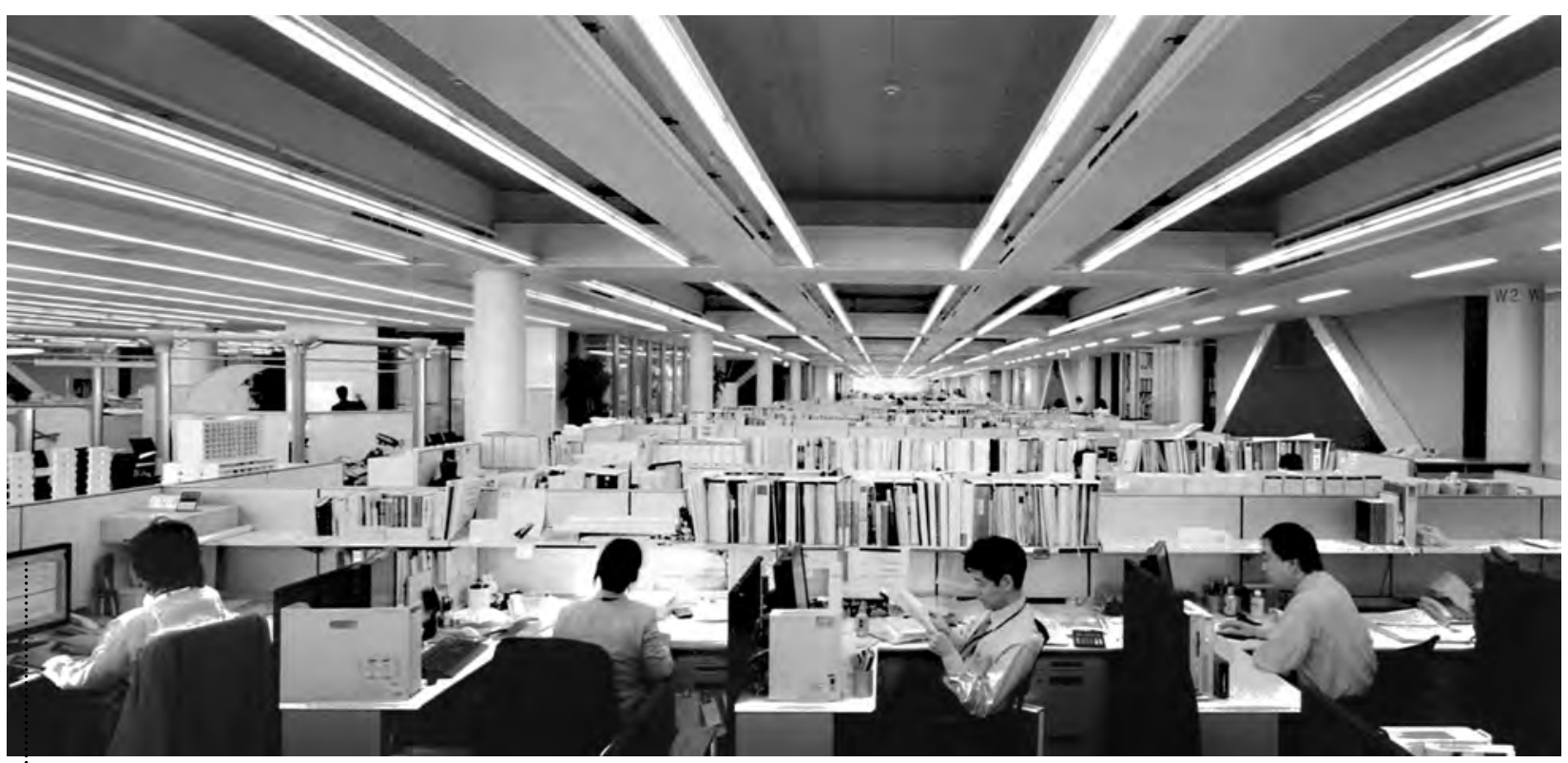

Figure 5. Takenaka Corporation Tokyo Main Office, interior (Source: Takenaka Corp.) 


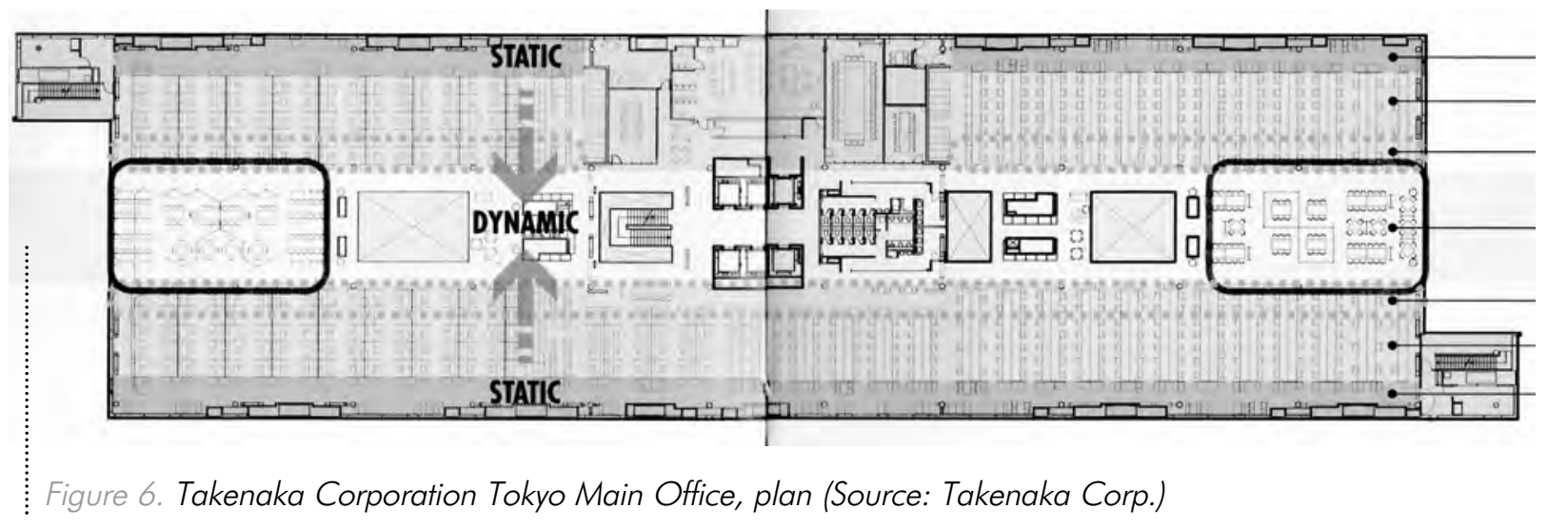

an urbanized area, especially more than three storeys high, is extremely rare. Wooden components are used on the façade, interior and some parts of the structure - all of which are made with standard sizes - providing easy availability in the future. While the lifespan of wood is shorter than of concrete, only two 'generic' types of wooden parts were used and are assembled with dry joints (screws) increasing their refitability in the future. This innovative solution of steel and timber ameliorate conventional applications of glve-laminated timber which does not lend itself to adaptability. State-ofthe-art computer modelling and manufacturing technology was needed to develop the low tolerances for such a precise solution for both structure and façade (Figure 8).

The designers of MK utilized the external periphery of the office space to create a strip of more casual and semi-open air spaces connecting

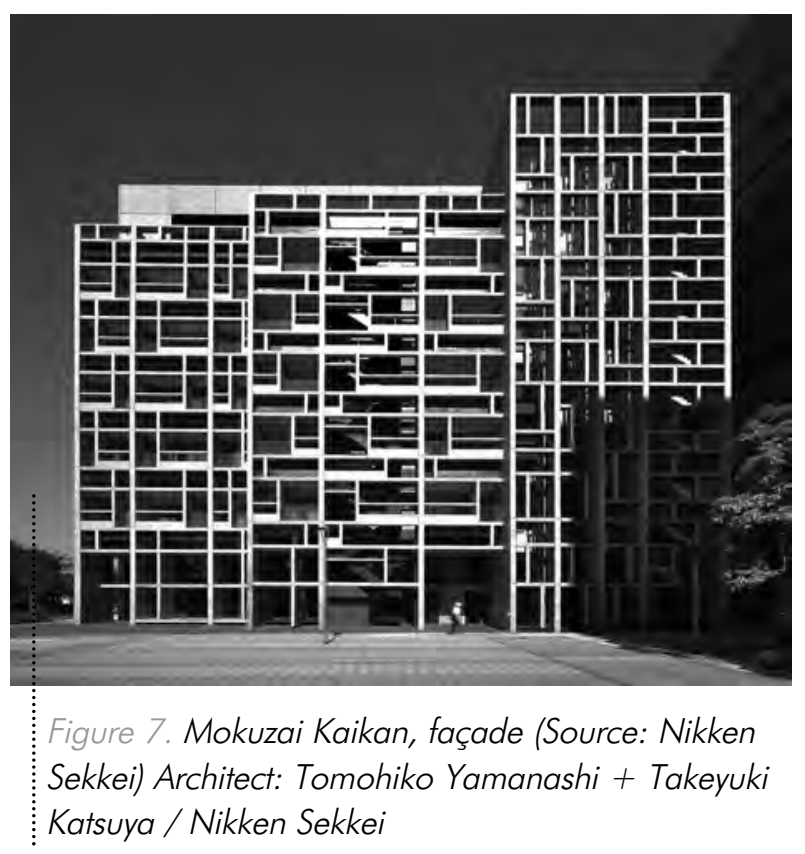

the office space to the outside environment (Figure 8). Like Takenaka headquarters, the building also decentralizes services to the outside which help allow for distributed control of the services amongst different tenants. However, contrary to Takenaka's non-uniform plan, MK utilizes a 'universal space' which they signify through a column-free work space.

\section{c-MA1 (small design atelier)}

This project involved the conversion of an 18-year old office building in central Tokyo, formerly a photo studio, into three residential units and an office suite. At the time of the project in 2003, the market for conversions in Tokyo was small, however the developer realized a potentially emerging market with several similar office buildings that were vacant in the city. The developer planned to create a prototype business model for the conver-

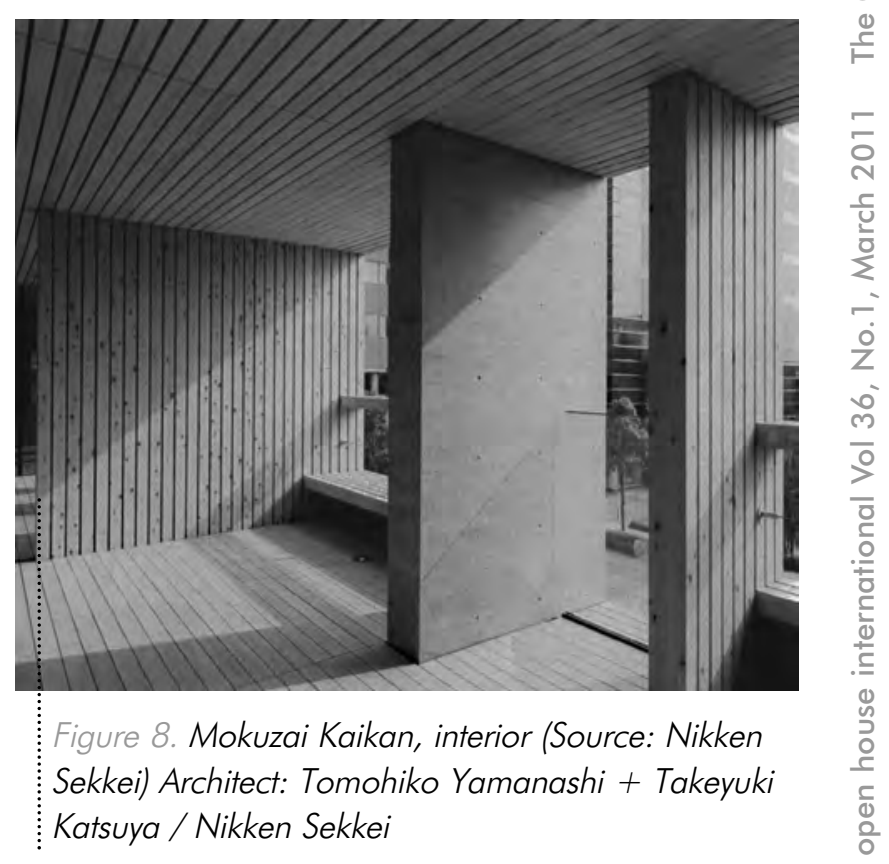




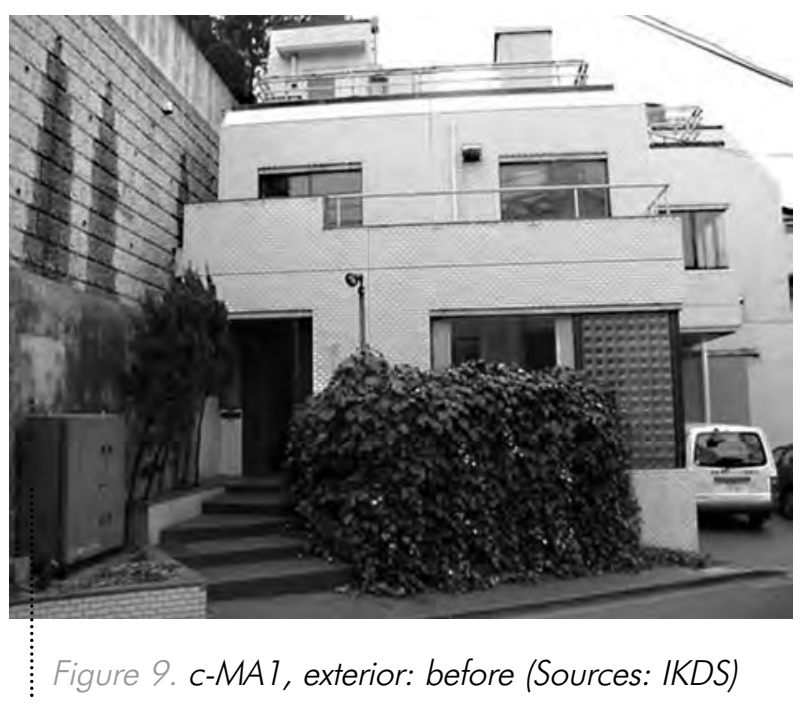

sion of three to four story office buildings, collaborating with an architect who could add unique value to the building (Figures 9 and 10). The business scheme aimed to accomplish two goals: 1) develop a business model for residential space; and 2) develop an alternative model of investment other than the normal upgrade, renovation or seismic rehabilitation. Residential use was a profitable market conversion because living space was at a higher premium in that area than offices (original use), and more residential floor area could be added as an incentive for residential development offered by the local government.

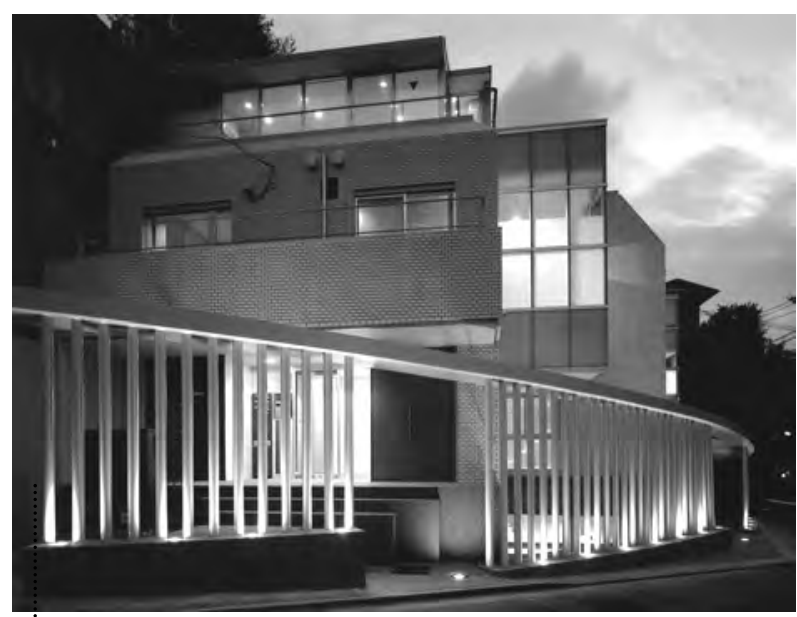

Figure 10. c-MA7, exterior: after (Sources: IKDS)

The architect and contractor had no experience in converting a building to a new use. The architect's design approach was to enhance the characteristics of the original building (e.g. provide a higher floor height for residential use). The designer perceived the building as part of the existing site which allowed the building to become integrated into his method of working and proposed solution. The team attempted to drive market value by emphasizing the uniqueness offered by the original characteristics - taller floor heights of rooms $(4.5 \mathrm{~m}$ and $3.8 \mathrm{~m})$ and split floor levels with small stairs linking the spaces (Figures 11 and 12).

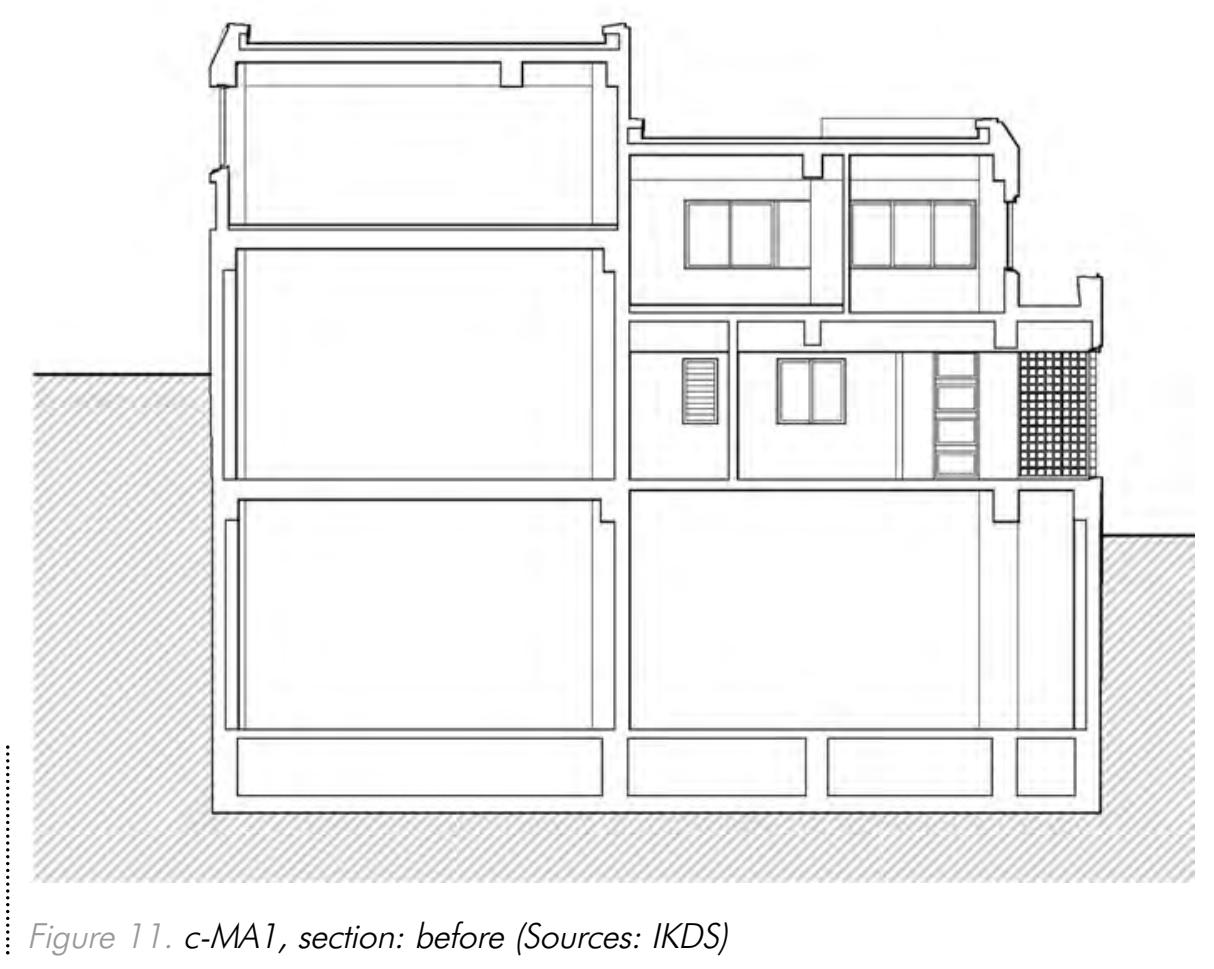




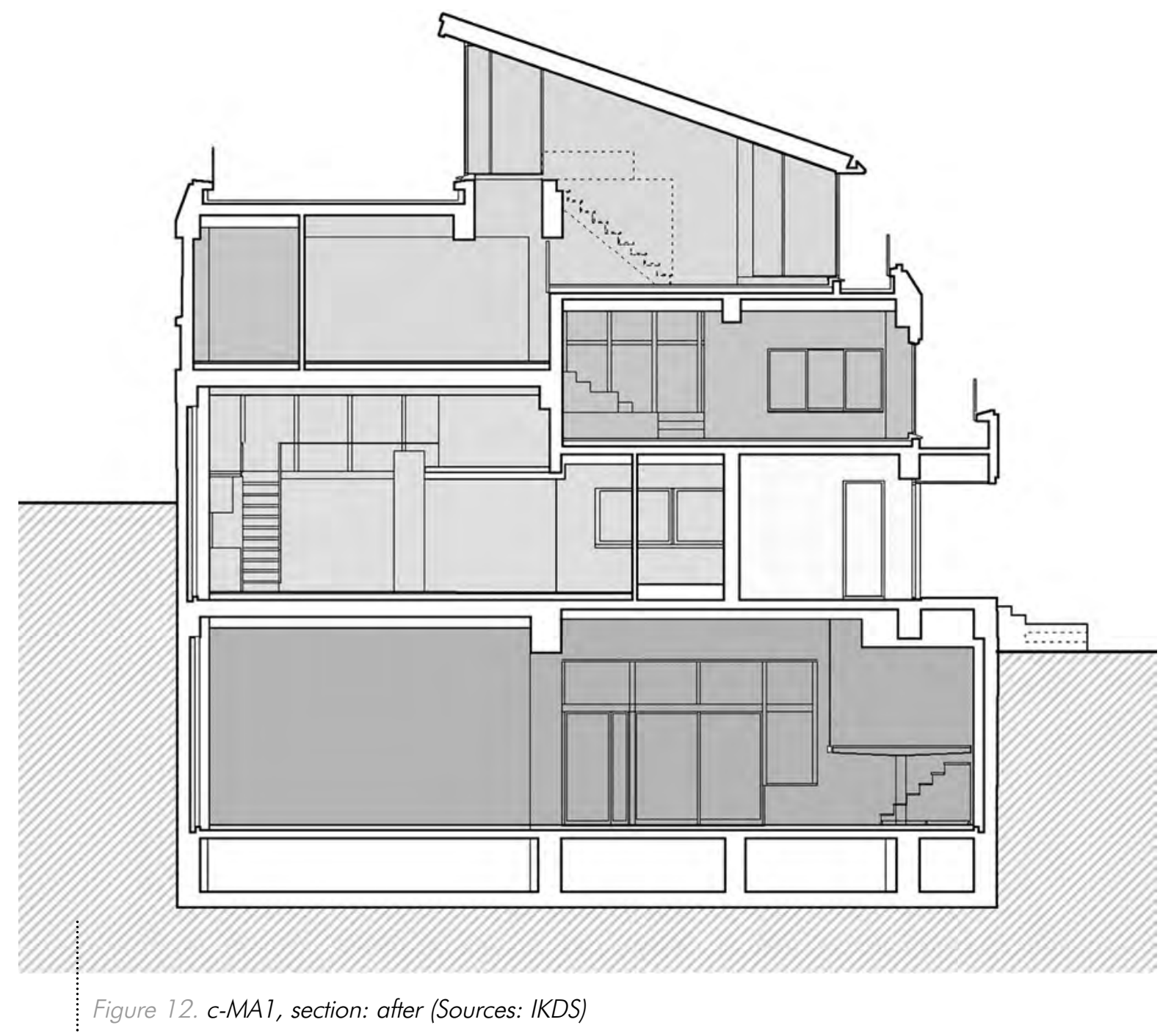

Exposing the features of the original building was also intended to enhance users' experience blending the new with the old.

Their lack of experience became evident with the difficulties encountered through the construction process (e.g. limited space for construction and elevator capacity). They had to think creatively in order to accomplish the design desires by carefully considering what parts of the building to dismantle to allow construction work and how to use existing components in combination with new parts (e.g. the canopy). In the end, due to the novelty of conversion work, a new and more integrated design approach was needed by both the architect and contractor utilizing innovative construction techniques at the component and building scale, for both new construction and the reuse of the existing building.

\section{CRITICAL DEPENDENCIES}

The following discussion expands the black box of adaptability which is often poorly defined, either in terms of requirements or solutions. It probes design criteria, obstacles and mindsets to establish links between the stereotypical understanding of adaptability and perceived external factors. It is also of interest that some comments cut across the practice typologies (universal) while others were only held by one, alluding to a particular perspective or approach. The section is organized into two dimensions: physical variables - critical design parameters associated with the physical object (e.g. storey height, plan depth, structural grid); and social variables - critical design contingencies conditioned by human factors (e.g. mindsets, policies, practice protocols). 


\section{Physical variables}

The physical variables construct the building's design structure - what it is, how it is constituted. Here, designers' responses are both direct (when asked what are the most critical physical parameters) and indirect (extrapolated from comments about projects). Floor to floor height was found to be the most critical design parameter and, on average, ranged from $2.5 \mathrm{~m}$ to $2.8 \mathrm{~m}$. A typical concern was with older office buildings (1960s) where the structural floor height is not large enough due to the demand for raised flooring to equip the latest service devices, making them difficult to renew. This however may change in the future with the increased use of wireless technologies; furthermore as illustrated in the case of c-MA1, conversion to residential use may be a viable option with typically lower storey heights being the industry norm. A second explicit and common parameter was the structural frame - as one designer commented, "If the building has a good enough structural frame, including large open spaces, there are no obstacles to realize adaptability".

While the most explicit parameters were floor to floor height and structural grid, all six practices mentioned the importance of services and the capacity (and cost) to be able to subdivide services to a minimum floor area due to greater demand to partition larger spaces/ buildings for more individval control. This is the case in both the Takenaka building and Mokuzai Kaikan above; whereas for c-MA1 services needed to be subdivided for each individual residential unit (opposed to the centralized unit that serviced the building prior). Other inferred parameters arose from common trends shaping office design reflected through changing user expectations including lower overall building heights and larger floor plates (mega floor) - e.g. Takenaka's headquarters. Enlarged personal space has increased the floor module as well from $3.0 \mathrm{~m}$ to $3.2-3.6 \mathrm{~m}$. Linking inside and outside through visual connection, inclusion and access of natural elements was a common point. Takenaka's office exhibited this characteristic through the central zone while Mokuzai Kaikan created a buffered zone along the periphery. Interestingly in a similar desire in $c-M A 1$, it was the idiosyncrasies of the existing structure beyond the ubiquitous frame that the 'new' designer wanted to capture. A final aspect considered by two of the practices (e.g. Mokuzai Kaikan) was the standardization and reuse of materials allowing for more efficient resource management and improved future availability.

\section{Social variables}

The capacity for architecture to change is not simply limited to the artefact itself, but is contingent to a process of design, construction and use; and is conditioned by a market, regulated by policies, and subject to stakeholder values. The social circumstance of greatest precedence resides in both supply and demand mindsets about adaptability. It was clear that while designers' admitted the need to design adaptable buildings, they presented clear reservations (e.g. possible reduction in work, a loss of character and identity in the building, scepticism to its realistic implementation). Designers also perceived that adaptable features would cost more which was reflected in the clients' reluctance to pay for additional initial capital costs; however, it was noted that government bodies were more amendable because they could invest more initially in an effort to reduce $\mathrm{CO} 2$ emissions through-life. Some of the designers attempted to rationalize the argument to clients through easier maintenance and response to changing tenant needs (whole life costs), but found it difficult to prove against shortterm gains. In all of the case studies presented above, the client or developer drove the demand for adaptability which was interpreted and facilitated through different design approaches resulting in a variety of solutions. At the same time, this revealed the designers' unanimous perception that the biggest individual benefactor and controller of adaptability is society - through a long-lasting and sustainable built environment. Without shifting attitudes and behaviours, a demand for adaptability would need to be driven from a higher level through government policies or from the bottom through user requirements. As one designer mentioned, "the easiest way to make a client do something is to point to a law or regulation."

Current regulations were seen primarily as an obstacle to adaptability including planning permission, fire resistance, safety regulations and seismic codes. However, in some cases, it was reflected on as being positive. In c-MA1, the demand for housing in the area created a government incentive 
to accommodate an increase in the floor area ratio calculation (FAR) allowing the developer to increase the scale of lettable space (by changing use). Additionally, in the case of Mokuzai Kaikan, the National Government changed the law regarding design requirements from specification to quality allowing easier compliance for wooden components. The ways in which regulations or incentives are operationalized in the design process can play a significant role in adaptability. A developer can receive incentives allowing them to exclude an amount of area from the FAR increasing their net lettable space (e.g. c-MA1) or to include more of a particular use (e.g. retail) by providing undersupplied space (e.g. affordable housing) increasing their overall profitability. These incentives, along with the reality that commercial buildings tend to be driven to maximize profitable space allowances, lock buildings into specific uses, making change of use difficult and reliant on shifts in government regulations.

Other points arose concerning the design process and how certain shifts have impeded or enabled adaptability to manifest. An obvious, but elusive shift was establishing early relationships with manufacturers. Good communication with the manufacturers at an early stage enabled the latest digital manufacturing technology to be applied resulting in a reduced number of components with a unified standard. A good relationship between contractor and architect in C-MA1 proved imperative when tackling the complications of new construction within an existing building. Along a similar line of thinking, another designer stressed the power of sharing motivation within the design team and client through creating a common goal as an incentive, such as an award for the design of their building.

The demand and cycle of the market was another significant factor mentioned by all the practices. The larger practices (general contractors and architectural design firms) saw the inclusion of adaptability as a reaction to clients' needs (a selling tool). Whereas, the design ateliers saw it more as a social responsibility beyond the clients' demand for specificity. A clear difference in perspectives emerged, reflecting the type of clients, scale of buildings, and perceived architectural roles and values. The ateliers found themselves more bound to their own design freedom pulled by their social role as designers; whereas, the larger, more business orientated, practices were shaped by the client or project specifics.

\section{LEARNING FROM/ MOVING FORWARD}

The analysis of these exploratory interviews in Japan have not only produced these insights into critical dependencies, but have also informed the development of the research through the refinement and expansion of the AF framework and shaping of the questions and format of future interviews. With regards to the framework, some interviewees had difficulty pinpointing what we meant by adaptability. It was clear that amongst the six interviews there were broader interpretations of adaptability and how it could be applied in industry either through the 'adaptability' of process, product or people. This was made evident from their responses including communication, technologies, regulations, and experiences - alluding to a wide range of sources. Whilst the design strategies (Figure 3) were comprehensible, their links to other factors discussed were not explicit and left to interpretation. All were capable of talking about adaptability; however, it was clear a finer degree of articulation would augment the discussion concerning future changes and the affects they might have on their proposed designs.

The experience clearly demonstrated the limits of the existing framework and led to the revision of our definition of adaptability (Schmidt III et al. 2010) along with the creation of additional diagrams illustrating key dimensions (Schmidt III et al. 2009a). The lessons accumulated had a direct impact on five of the consequential diagrams (strategies, sources, design perspectives, linking table, and project pull). One example is the creation of the 'sources' diagram which took our six strategies for adaptability and placed them in a broader contextual spectrum including design intelligence (e.g. philosophy, experiences,), rules (e.g. services, structure), policy (e.g. planning and building regulations, taxes), and products (e.g. standard details, iso standards). This allowed us to contextualize the array of responses, and empha- 
size their relationship to time by organizing them ranging from more timeless aspects (intelligence, culture) to more time bound (products, market).

With respect to our ongoing design practice investigation, the revised definitions and diagrams were summarized on an A4 sheet, distilling the core concepts as an invaluable tool for clarification and reference throughout the second stage of interviews. Questions have been posed to elucidate the role of the practice as an arena for adaptability. This tactical shift is captured and conveyed through the use of the 'project pull' and 'practice disposition' diagrams that have enabled conversations around the practice and served as a convenient method for characterizing practice typologies. The research reported here has thus enabled a richer conversation to take place within stage two.

\section{CONCLUDING REMARKS}

The cultivation of adaptability in Japan has a long history from traditional construction to more recent government led initiatives to promote the longevity of their housing stock. Historically, the adaptable attributes found in traditional designs were primarily driven as methods to accommodate the diversity of everyday life at the scale of the component (change of task, space or performance), as opposed to increasing the longevity of the building - through additional types of changes at a building scale (change of scale, use or location). The sustainability agenda has brought new interest in the latter, and many of the principles established by Japan's traditional housing design provide an interesting starting point for other contexts. Its revival has been brought about by a top-down approach of reinstating adaptable principles into the quality of construction, but will need to be matched with a shift in the mindsets of professionals or a customerdriven demand of the market by society.

Whilst historical efforts in Japan have embedded an understanding in both the architectural profession and practice of important concepts around adaptability, implementation has been a slow journey. As a profession, one of the questions the research raises is to what extent does a designer have control over adaptability? The design, manufacture and operation of buildings present a highly complicated process and slowly evolving product where control is inevitably distributed - it relies on the owners' wiliness, government agendas, the capacity of constructors and manufacturers, society's appreciation, and most importantly the users' appropriation. As a practice, perceived roles and values, types of clients and scales of buildings will inevitably influence the perception and application of adaptability, as shown through the three case studies offering distinct solutions in the context of modern office facilities - illustrating there is no one solution for adaptability. Further unpacking of the 'static' building into the design and use processes - moving architecture - is imperative to understand the influence of design practice culture in shaping the evolving solution.

Research into adaptability requires the effective communication of sufficiently sophisticated descriptions of key concepts to allow an informed conversation between professionals and with clients and users. Expanding the 'black box' of adaptability and unfolding the critical dependencies that link adaptability to a multitude of contextual dimensions - placing architecture in context and time - is essential for its successful manifestation. Like many other philosophical design concepts in complex processes, adaptability benefits from a mutual understanding, good relationships, communication, integration, and shared goals amongst team members. Whilst economic and regulatory obstacles are commonly cited, we should not underestimate the sociological impact of professional and practice attitudes and mindsets - shiffing architectural dictums from form follows function to form accommodates change.

\section{ACKNOWLEDGEMENTS}

This research project is funded UK's Engineering and Physical Sciences Research Council (EPSRC) through the Innovative Manufacturing and Construction Research Centre at Loughborough University. A special thanks to the designers interviewed and Professor Matsumura. 


\section{REFERENCES}

BARLOW, J., CHILDERHOSUE, P., GANN, D., HONG-MINH, S., NAIM, M., OZAKI., R., 2003. Choice and delivery in housebuilding: Lessons from japan for UK housebuilders. Building Research \& Information 31 (2), pp. 134.

BARLOW, J. and OZAKI, R., 2005. Building mass customised housing through innovation in the production system: lessons from japan. Environment and Planning A, 37, pp. 9.

BOTTOM, D., GANN, D., GROAK, S. and MEIKLE, J., 1996. Innovation in Japanese Prefabricated House-Building Industries. 139. London: CIRIA.

BRAND, S. 1994. How Buildings Learn: What Happens After They're Buitt, Penguin Books.

BUNTROCK, D., 2002. Japanese Architecture as a Collaborative Process. London: Spon Press.

DOUGLAS, J., 2006. Building Adaptation. 2nd edn. Great Britian: Elsevier Ltd.

DUFFY, F., 1990. Measuring Building Performance. Facilities, 8(5), pp. 17.

GANN, D., 1996. Construction as a manufacturing process? Similarities and difference between industrialized housing and car production in Japan. Construction Management and Economics, 14, pp. 437.

GIBB, A. AUSTIN, S. DAINTY, A. DA VISON, N. PASQUIRE, C. 2007. Towards adaptable buildings: Pre-configuration and reconfiguration - two case studies, ManuBuild lst International Conference, Rotterdam.

HIRAl, K., 1998. The Japanese House Then and Now. Ichigaya Publishing Co., Ltd.

KENDALL, S. JONATHAN, T. 1999. Residential Open Building, Taylor \& Francis.

LEUPEN, B., HEIJINE, R. and ZWOL, J.V., eds, 2005. TimeBased Architecture. Rotterdam: 010 Publishers.

MINAMI, K. 2006. A Study on the Continues Customization of an adaptable housing by KEP System, International Conference on Adaptable Building Structures, Einthoven.

MLIT (Ministry of Land, Infrastructure, Transport and Tourism) JAPAN, URBAN RENAISSANCE AGENCY, JAPAN HOUSING FINANCE AGENCY, THE BUILDING CENTER OF JAPAN, 2008. A Quick Look at Housing in Japan, 6th Edition, The Building Center of Japan.

NEXT 21 EDITORIAL COMMITTEE, 2005. NEXT 21, XKnowledge Co., Lłd. (Japanese)

NUTE, K., 2004. Place, Time, and Being in Japanese Architecture. London: Routledge.

RUSH, R.D., ed, 1986. The Building Systems Integration Handbook. New York: John Wiley \& Sons.
SCHMIDT III, R. EGUCHI, T. AUSTIN, S. GIBB, A. 2009a. Adaptable futures: A 21 st century challenge, Paper presented at Changing Roles - New Roles; New Challenges, Rotterdam.

SCHMIDT III, R., AUSTIN, S. and BROWN, D., $2009 \mathrm{~b}$. Designing Adaptable Buildings, Harnessing the Power of Information, Oct 12-13 2009, South Carolina, USA.

SCHMIDT III, R. EGCUHI, T. AUSTIN, S. GIBB, A. 2010. A critical look at the meaning of adaptability in the building industry. CIB W104 16th International Conference "Open and sustainable Building", Bilbao (downloadable at www.adaptablefutures.com).

SCHNEIDER, T. and TILL, J., 2007. Flexible Housing. 1st edn. Oxford: Elsevier Ltd.

SLAUGHTER, E.S., 2001. Design strategies to increase building flexibility. Building Research \& Information, 29(3), pp. 208.

TAKENAKA CORPORATION. 2005. Takenaka Corporation; Tokyo Main Office Building Department, TAKENAKA DESIGN WORKS TOKYO 03 Winter 2005.

THE BUILDINDG CENTER OF JAPAN, 2008. A Quick Look at Housing in Japan, 6th Edition, The Building Center of Japan.

TILL, J., 2009. Archifecture Depends. Cambridge: MIT Press.

UTIDA, Y. 2002, The Culture and Construction of Architecture Today: A View from Japan, Ichigaya Publishing Co., Ltd.

VENTURI, R. and SCOTT BROWN, D., 2004. Architecture as Signs and Systems. Cambridge, MA.: Belknap Press.

\section{Authors' Addresses}

Toru Eguchi, Assistant Professor,

Yokohama National University, Japan

t.eguchi@ynu.ac.jp

t.eguchi@lboro.ac.uk

Robert Schmidt III, Research Associate, Loughborough University, United Kingdom

Andrew Dainty, Professor, Loughborough University, United Kingdom

Simon Austin, Professor, Loughborough University, United Kingdom

Alistair Gibb, Professor, Loughborough University, United Kingdom 